\title{
EL PAPEL DE LOS AGENTES \\ EN LA DINÁMICA URBANISTICA Y TERRITORIAL DURANTE EL BOOM INMOBILIARIO (1996-2006) EN LA LLANURA DEL ALT EMPORDÀ (GIRONA)
}

\author{
Sergi Cuadrado Ciuraneta \\ Departamento de Geografía. Universidad Autónoma de Barcelona \\ Sergi.Cuadrado@uab.cat
}

\section{RESUMEN}

El artículo analiza el papel de los agentes en la dinámica urbanística y territorial durante los años del boom inmobiliario (1996-2006): administraciones públicas (ayuntamientos y Generalitat), plataformas de defensa y movimientos vecinales, agentes privados vinculados a la actividad urbanística (propietarios de suelo y promotores inmobiliarios) y empresariado de los sectores tradicionalmente relevantes (turístico y agropecuario). El estudio se realiza sobre la llanura del Alt Empordà (Girona), que puede resultar representativa de otros espacios litorales de la geografía española.

Palabras clave: burbuja inmobiliaria, agentes urbanísticos y territoriales, procesos de urbanización, metropolización, llanura del Alt Empordà.

\section{ABSTRACT}

The paper analyzes the role of agents in the urban and territorial dynamics during the Real-Estate boom years (1996-2006): public administrations (municipalities and regional government), defense platforms and neighborhood movements, private agents involved in urban development (landowners and developers) and members of traditionally important

Fecha de recepción: noviembre 2015.

Fecha de aceptación: noviembre 2016. 
sectors (tourism and agricultural activities). The study is performed on the plain of Alt Empordà (Girona), which may be representative of other coastal areas of the Spanish geography.

Keywords: Real-Estate bubble, urban and regional agents, urbanization processes, metropolization, plain of Alt Empordà.

\section{INTRODUCCIÓN}

Este artículo ${ }^{1}$ aborda el análisis de los agentes que participan en la dinámica urbanística y territorial en una zona litoral como la llanura del Alt Empordà (Girona), que a partir de los años sesenta del siglo pasado experimentó un fuerte desarrollo del turismo, pero que más recientemente ha experimentado procesos más complejos, que resultan un buen ejemplo de las dinámicas de metropolización del territorio.

El boom inmobiliario se erigió, en el cambio de siglo, en un importante factor de desarrollo, contribuyendo al incremento de la construcción y de la dispersión de la urbanización. A partir de mediados de los noventa se asiste en España a un aumento continuado de la demanda de vivienda, de la producción residencial, del precio del suelo y de la consideración de la vivienda como valor de cambio, así como al decantamiento de buena parte de la economía hacia la construcción (Fernández Durán, 2006; Burriel, 2008; Naredo y Montiel, 2011). Estas dinámicas encontraron un escenario privilegiado en las zonas costeras (Valenzuela, 2007; Gaja, 2008; Obiol y Pitarch, 2011), caracterizadas por un importante componente inversor, y donde a menudo se ha llegado a difuminar la divisoria entre turismo e inversión inmobiliaria (Mazón y Aledo, 2005; Vera, 2005; Villar y Fernández Tabales, 2013). Este proceso generó una enorme burbuja inmobiliaria (Rodríguez López, 2006; García Montalvo, 2006; Bernardos, 2009), por las fuertes expectativas de compradores e inversores. Una situación finalmente insostenible, que condujo a una grave y persistente crisis económica (Romero, 2010).

El objetivo del artículo es esclarecer el papel de los agentes que intervienen en los procesos de urbanización, incidiendo en la constitución de un determinado patrón urbanístico y territorial. Esta cuestión se analiza en un período determinante para nuestro país, los años del boom inmobiliario (1996-2006), y en un área, la llanura del Alt Empordà, representativa de otros muchos espacios de la geografía española que, sometidos a las fuertes presiones del turismo, luego han evolucionado hacia patrones territoriales más complejos, con la emergencia de nuevos procesos, como el residencialismo.

Primero se presentará el área de estudio, como un buen ejemplo de la metropolización del territorio. En segundo lugar se esbozaran las características metodológicas del estudio, basado en entrevistas a representantes de entidades y colectivos del territorio y el análisis a partir de un inventario de los agentes. En tercer lugar se discute el papel de los agentes en la dinámica urbanística y territorial: administraciones (ayuntamientos y Generalitat), pla-

$1 \quad$ El artículo se deriva de la tesis doctoral La Metropolitanització a la plana de l'Alt Empordà. Exemple d'un nou model territorial a Catalunya (Cuadrado, 2012), cuyos directores han sido los profesores Antoni Durà y Helena Estalella. Dicho trabajo se ha enmarcado en el grupo de investigación INTERFASE (SGR 2014-1499), cuya investigadora principal es la Dra. Françoise Breton. 
taformas de defensa y movimientos vecinales, agentes privados vinculados a la actividad urbanística (propietarios de suelo y promotores inmobiliarios) y sectores económicos tradicionalmente relevantes (empresariado turístico y campesinado). Finalmente se extraen unas conclusiones, tratando de discernir cuales han sido los agentes más determinantes.

\section{EL ALT EMPORDÀ, EJEMPLO DE LA METROPOLIZACIÓN DEL TERRITORIO}

La llanura del Alt Empordà, situada en el noreste de Cataluña, en el extremo septentrional de la Costa Brava, incluye veintiún municipios² (Figura 1). Se trata de una zona donde se despliegan el turismo, la agricultura y las actividades de conservación, y donde entran en contacto los espacios urbanizados turísticos y no turísticos, los espacios agrícolas y los espacios protegidos de interés natural (Saurí et al, 2000; Pavón et al, 2003). La economía está dominada por los servicios y la construcción, aunque la agricultura todavía mantiene un papel importante (Cals, 1987; Nogué, 2000). Esta estructura productiva se haya muy condicionada por el turismo, que se desarrolló desde los años sesenta del siglo pasado. La costa del Alt Empordà, como muchas otras del litoral español, experimentó fuertes crecimientos relacionados con la llegada de visitantes y el desarrollo de la infraestructura de alojamiento y la segunda residencia (Cals, 1982, Barbaza, 1988; Fraguell, 1994), con importantes consecuencias sobre el territorio, el medio ambiente y el paisaje (Martí, 2012). Los crecimientos, que llegaron a multiplicar por diez la superficie urbanizada -de 247,4 ha. (el 0,7\% del territorio) en 1957 a 2.349,9 ha. (el 6,9\%) en 1997 (Cuadrado et al, 2007)-, se realizaron sobre todo a primera línea de costa, sobre antiguos campos de cultivo y humedales (Breton y Romagosa, 2002). En los años ochenta, los ayuntamientos democráticos no consiguieron enderezar la situación, la construcción de segundas residencias continuó (Vicente y Gutiérrez, 2004) y la oferta turística se decantó hacia esta forma de alojamiento (Oliver, 2005).

A principios de los noventa se empezaron a experimentar cambios relacionados con la evolución de las actividades turísticas (Donaire et al, 1997), pero también con las tendencias demográficas, con el incremento de la población y la movilidad, en relación con la evolución del mercado laboral y los precios de la vivienda (Pavón, 2002; Gutiérrez y Castañer, 2003). Se produjo una mayor presencia de poblaciones flotantes de origen extranjero (jubilados inmigrados del norte de Europa o inmigrantes laborales de otros continentes), que incide en el fenómeno del residencialismo; un concepto al que se han otorgado diversas connotaciones pero que en el caso catalán se ha utilizado de forma amplia y en cierto modo dual (Donaire, 2005). En primer lugar, para hacer referencia a la estrategia de la recreación del espacio urbano que utilizan algunas áreas turísticas litorales para hacer frente al cambio de modelo turístico, y que consiste en la apuesta por el incremento poblacional y la reconversión de los núcleos turísticos en ciudades con servicios de carácter urbano y una mayor centralidad (Donaire y Mundet, 2001). En segundo lugar, para describir la transformación de determinadas áreas turísticas, con la pérdida de peso del turismo residencial y la progresiva conversión de las segundas en primeras residencias (Fraguell, 2004).

2 Los criterios utilizados para definir este ámbito son de tipo geomorfológico (llanura sedimentaria), hidrogeológico (acuíferos y relieves que los rodean) y administrativo (límites municipales). El ámbito así delimitado se extiende desde Roses hasta la Escala y, hacia el interior, hasta los límites del municipio de Figueres. 


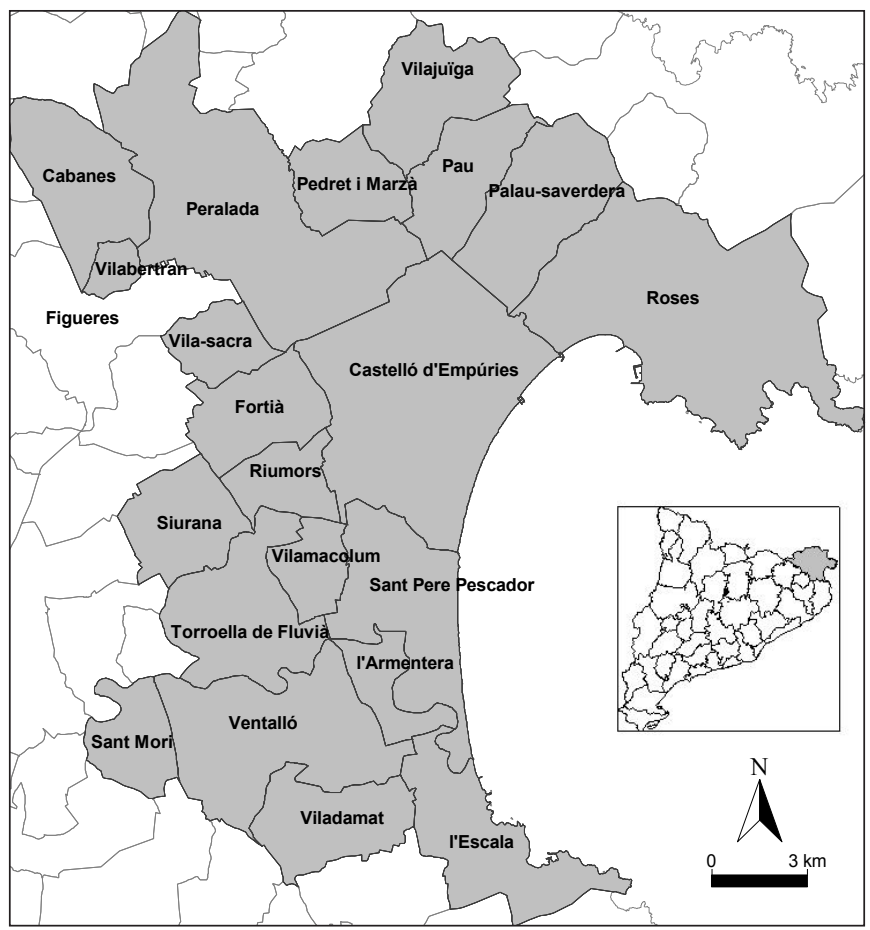

Fuente: elaboración propia.

En este contexto se enmarca la fiebre constructiva iniciada a mediados de los noventa, que en el caso de esta área, mientras que para unos se encuentra relacionada con la expansión de la segunda residencia (Oliver, 2005), para otros responde a dinámicas comunes en todo el territorio (Cals, 2005; Pié, 2005). El aumento de la presión constructiva implica un crecimiento de 186,1 ha., llegando la superficie urbanizada al 7,9\% del territorio en el año 2004 (Cuadrado et al, 2016), y se traduce en el salto de la urbanización a segunda línea de costa (Vicente y Gutiérrez, 2004; Nogué, 2005), a partir de los principales núcleos urbanos y a lo largo de las principales vías de comunicación (Valdundiel, 2014), con la constitución de tres tipologías de paisaje urbano: ensanches, urbanizaciones y polígonos.

La intensificación de la presión constructiva fue comportando la aparición de una serie de proyectos de urbanización, en ocasiones de una considerable envergadura (Esteban y Tarroja, 2004; Tarroja, 2005; Tarroja et al., 2006, 2007), la cual cosa generó un estallido de la conflictividad territorial y la aparición de las denominadas "plataformas cívicas en defensa del territorio", igual que sucedió en otros muchos lugares de Catalunya (Nel·lo, 2003). Además, este clima de movilización ciudadana condujo a la celebración, en 2004, de un nuevo "Debate Costa Brava" (COAC, 2005), como el que había tenido lugar treinta años antes (AAVV, 1978). Finalmente, se produjo la actuación de la Generalitat, que a partir de 2004 puso en marcha un 
ambicioso programa de planificación de ámbito supramunicipal, con el que se acabó estableciendo, en el año 2010, el sistema de planeamiento territorial en toda Cataluña, con la finalización de los diferentes planes territoriales parciales, que llevaban pendientes desde la aprobación definitiva del Plan Territorial General de Cataluña, en 1995 (Nel·lo, 2012), y que incluye algunas figuras de planeamiento de gran incidencia para este área (Cuadrado, 2008).

Se configura, así, un complejo sistema de asentamientos, que en su momento estuvo muy determinado por el turismo y la segunda residencia, y que más recientemente ha experimentado las consecuencias de las dinámicas de dispersión metropolitana, de urbanización del medio rural y de redefinición de los espacios turísticos (Cuadrado et al, 2016). Este nuevo tipo de configuración resulta un buen ejemplo de lo que Indovina (2003) ha calificado como de nueva metropolización del territorio, entendida como la integración en un único conjunto de diferentes áreas urbanas, entre las que se establecen relaciones e interdependencias, y que alcanza una geometría variable en función de las diferentes actividades, y que Nel·lo (2002) constató, para el caso catalán, en su Ciudad de ciudades, al concluir que el sistema urbano catalán funciona, cada vez más, como una única unidad funcional, conectada por complejos flujos e interrelaciones, y desarrollada bajo unas mismas dinámicas, comportamientos y estilos de vida.

\section{METODOLOGÍA}

Los resultados presentados forman parte de una investigación más amplia, que ha combinado métodos cuantitativos y cualitativos (Cuadrado y Durà, 2014). El estudio del papel de los agentes en la dinámica urbanística y territorial se ha realizado a partir de entrevistas en profundidad. Las entrevistas se realizaron a una serie de informantes clave, portavoces de diferentes colectivos, descartando las entrevistas a personas particulares.

Se entrevistó a veinticinco personas de diferentes instituciones y organizaciones: administraciones, asociaciones empresariales y sectoriales, colegios profesionales, sindicatos y asociaciones de vecinos y entidades cívicas (ver Tabla 1). También se entrevistó a varias personalidades del ámbito académico catalán que se caracterizaban por combinar esta condición con la planificación y la gestión de las dinámicas territoriales, urbanísticas y paisajísticas desde la administración (Oriol Nel·lo y Jaume Busquets, Secretario de Planificación Territorial y Subdirector General de Paisaje de la Generalitat, respectivamente), por su participación en comisiones donde se dirime sobre estas cuestiones (Salvador Anton, miembro de la Ponencia Técnica de la Comisión de Urbanismo de Tarragona) o, como es el caso de Joan Cals, por haber tenido un importante papel en el Debate Costa Brava, proceso de participación de gran relevancia para el área analizada celebrado a mediados de los setenta (AAVV, 1978).

Las entrevistas consistieron en unos diálogos abiertos, en los cuales las personas entrevistadas aportaron su visión sobre una diversidad de aspectos como la idoneidad de los crecimientos urbanísticos, las causas de estos crecimientos, las motivaciones de los diversos flujos migratorios, los cambios en el turismo, el papel de los diferentes agentes implicados en los crecimientos, la evolución de las dinámicas territoriales, las perspectivas de futuro, etc. 
Tabla 1

ENTREVISTAS REALIZADAS

\begin{tabular}{|l|}
\hline Entidad / Organismo \\
\hline Administraciones \\
\hline Ayuntamiento de Castelló d'Empúries \\
\hline Ayuntamiento de Sant Pere Pescador \\
\hline Ayuntamiento de Torroella de Fluvià \\
\hline Ayuntamiento de Viladamat \\
\hline Ayuntamiento de Vilajuïga \\
\hline Parque Natural de los Aiguamolls del Alt Empordà \\
\hline Patronato de Turismo Costa Brava Girona \\
\hline Servicios Territoriales de Urbanismo de Girona \\
\hline Asociaciones sectoriales v de empresarios \\
\hline Asociación de Empresarios de Actividades de Hostelería del Alt Empordà \\
\hline Asociación de Pagesos y Cortalers de Castelló d'Empúries \\
\hline Cámara de Comercio, Industria y Navegación de Girona \\
\hline Comunidad de Regantes de la Muga Dreta \\
\hline Gremio de Promotores y Constructores de Edificios de Girona \\
\hline Colegios profesionales \\
\hline Colegio de Agentes de la Propiedad Inmobiliaria de Girona y Provincia \\
\hline Colegio de Aparejadores y Arquitectos Técnicos de Girona \\
\hline Colegio de Arquitectos. Delegación del Alt Empordà \\
\hline Sindicatos \\
\hline Comisiones Obreras. Delegación del Alt Empordà \\
\hline Unió de Pagesos. Delegación del Alt Empordà \\
\hline Unión General de Trabajadores. Delegación del Alt Empordà \\
\hline Asociaciones v entidades cívicas \\
\hline Asociación de Vecinos y Usuarios de la Urbanización Bon Relax \\
\hline Asociación Al-Jamaa (Sant Pere Pescador) \\
\hline Asociación de Vecinos de Palau-saverdera \\
\hline Asociación de Vecinos del Barri El Temple \\
\hline Plataforma Cívica contra la Construcción Masiva de Castelló d'Empúries \\
\hline Plataforma Salvem l'Empordà \\
\hline
\end{tabular}

Fuente: elaboración propia.

A fin de estructurar el análisis, se confeccionó un inventario de los agentes. Resultó muy útil el bagaje adquirido mediante la revisión bibliográfica sobre el ámbito de estudio, el trabajo de campo y la recopilación de noticias de prensa, pero fue definitiva la recopilación de bibliografía sobre los actores que participan en la producción del espacio urbano, que se circunscribió al ámbito catalán, para recoger aportaciones sobre el mismo contexto territorial que se debía analizar.

Así se consultaron obras que se caracterizan por entender la ciudad como un producto social. Se trata de los trabajos de Roca y Massana (1972), que analizan el papel de las clases hegemónicas que dominan el proceso de urbanización de Barcelona. Para estos 
autores, los agentes que configuran la realidad urbana son los grandes propietarios urbanos, las grandes empresas, el Estado y los agentes públicos locales. En la misma línea, para Capel (1974), la producción del espacio urbano es el resultado de las prácticas de unos agentes que actúan dentro del sistema capitalista y que, con sus intereses, modelan el crecimiento urbano. Este autor identifica a los propietarios de los medios de producción, los propietarios del suelo, los promotores inmobiliarios y las empresas de construcción y los organismos públicos. Tatjer (1979), a su vez, analiza el papel de los propietarios de bienes inmuebles en la organización del espacio urbano, teniendo en cuenta la diversidad de formas de la propiedad urbana. De forma más específica, Solà Morales (1974) se centra en los propietarios del suelo y su apropiación de las plusvalías en el caso de las áreas de urbanización marginal de la Barcelona de los años sesenta y setenta. Resulta de especial interés la comunicación de Teixidor (1978), en el Debate Costa Brava, que analiza los agentes que intervinieron en el proceso de urbanización de la costa: propietarios de suelo, promotores privados, constructores, técnicos y gestores, usuarios, administración pública y población en general. Finalmente, Vilagrasa (1984) analiza la relación en el caso de Lleida entre los agentes privados, que se apropian de las rentas territoriales, y que habrían evolucionado desde el tradicional propietario de suelo hasta el promotor inmobiliario profesional, y las instituciones, que deben orientar el proceso de acumulación derivado de la producción del espacio urbano.

Con el cambio de siglo parece haber un avivamiento del estudio de los agentes urbanos, con una característica diferencial, la introducción de elementos alejados del análisis de la lógica capitalista, y un mayor peso del examen de agentes diferentes de los económicos, ya sean técnicos y profesionales, asociaciones y entidades o medios de comunicación. Capel (2005) analiza, para el caso de Barcelona, el juego establecido entre administraciones y iniciativa privada, al tiempo que introduce la figura de los técnicos, que también desempeñan un papel relevante, y posteriormente reemprende y actualiza la reflexión alrededor de estas cuestiones en el tercer volumen de La morfología de las ciudades (Capel, 2013). Del mismo modo, Cruz (2006), al analizar los conflictos urbanísticos, cuya resolución acaba incidiendo en el planeamiento y, por tanto, en la construcción de ciudad, identifica a plataformas de ciudadanos, asociaciones de vecinos, grupos de defensa del territorio, expertos independientes, medios de comunicación y administraciones locales. La inclusión de estos otros agentes se hace en un clima de creciente conflictividad territorial en toda Cataluña (Nel·lo, 2003), que lleva a unos a hablar de "cultura del no" y a otros a plantear la necesidad de "una nueva cultura del territorio" (Ferran y Casas, 2008).

Con todo, no se olvida el papel de los agentes económicos, como los promotores, que en esta época experimentan la infiltración del capital extranjero, una creciente vinculación con el sistema financiero y la diversificación de las áreas de negocio, incluyendo el ámbito internacional (Sánchez, 2003). En la misma línea, Boixader (2005) identifica como agentes que intervienen en la renovación del Poblenou de Barcelona a administración, empresas industriales y de servicios, promotores inmobiliarios, propietarios de suelo, propietarios de techo y ciudadanos en general. Finalmente, González Reverté (2004) se fija en el sector inmobiliario, la administración local y los grupos conservacionistas cuando analiza el proceso de urbanización del Baix Penedès. 
A partir de estas lecturas, y el propio contenido de las entrevistas, se confeccionó el inventario de los agentes que intervienen en la dinámica urbanística y territorial del área analizada:

- Administraciones públicas. Establecen la normativa que regula la actuación de los privados, corrigiendo posibles deficiencias y salvaguardando los intereses de la ciudadanía. Los ayuntamientos se encargan de definir los futuros crecimientos, y de velar para que las actuaciones de propietarios y promotores se ajusten a la normativa. La Generalitat tiene competencias sobre ordenación territorial, ejerce el control de los planeamientos municipales y presta asistencia técnica y jurídica a los municipios.

- Plataformas de defensa y movimientos vecinales. Ejercen un papel vigilante de las administraciones, y presionan para conseguir lo que, desde su punto de vista, supone unas mejores condiciones de vida para la ciudadanía. Se trata de plataformas, asociaciones y grupos de defensa, que normalmente colaboran, compartiendo informaciones, recursos y estrategias, aunque a veces puedan mantener posiciones divergentes.

- Agentes privados vinculados a la actividad urbanística. Proponen desarrollos urbanísticos con el objetivo de conseguir la máxima rentabilidad económica, en base a las posibilidades que les ofrece la legislación, deviniendo los responsables de la producción física del espacio urbano. Los propietarios de suelo buscan maximizar el valor de los terrenos, vendiéndolos o especulando con ellos. Los promotores impulsan las obras de edificación, generalmente para su comercialización.

- Principales sectores económicos. Los propietarios de los medios de producción necesitan suelo para desarrollar sus actividades, y entran en conflicto con otros posibles usos. Se ha hecho una aproximación al papel desempeñado por el tejido empresarial de los sectores tradicionalmente representativos del área: actividades agropecuarias y turismo.

\section{EL PAPEL DE LOS AGENTES EN LA DINÁMICA URBANÍSTICA Y TERRITORIAL}

A continuación se procede al repaso del papel que ejercen los diferentes agentes en la dinámica urbanística y territorial del área de estudio, es decir, administraciones públicas (ayuntamientos y Generalitat), plataformas de defensa y movimientos vecinales, agentes privados vinculados a la actividad urbanística (propietarios de suelo y promotores inmobiliarios) y empresariado de los sectores económicos tradicionalmente relevantes (turístico y agropecuario).

\section{IV.1. Las administraciones públicas}

Las administraciones que ejercen las competencias en urbanismo y ordenación del territorio en Cataluña son los ayuntamientos y la Generalitat. Los ayuntamientos formulan el planeamiento urbanístico general y gestionan la ejecución del mismo a través de las diferentes figuras de planeamiento derivado. A su vez, la Generalitat establece las directrices generales en ordenación del territorio y lleva a cabo el control de la actuación urbanística. Estas fun- 
ciones se ejercen desde el Gobierno, a través de la acción del Departamento de Territorio y Sostenibilidad ${ }^{3}$ y de sus órganos y entes públicos (Dirección General de Ordenación del Territorio y Urbanismo, Instituto Catalán del Suelo, Servicios Territoriales de Territorio y Sostenibilidad, etc.), y desde las comisiones de urbanismo (la Comisión de Urbanismo de Cataluña y las diferentes comisiones territoriales).

\section{IV.1.1. Los ayuntamientos}

En primer término, el interés de los ayuntamientos en los crecimientos urbanísticos habría sido el de surtir la demanda de vivienda de los habitantes del municipio. Sin embargo, muchos municipios acaban recibiendo población de otros lugares, por lo que el desarrollo urbanístico no termina satisfaciendo las demandas de vivienda más locales. Los crecimientos incluso pueden redundar en un perjuicio para la población local, ya que los elevados precios de la vivienda y su crecimiento acelerado durante los años del boom, en algunos lugares habrían supuesto la marcha de ciertos grupos de población (por ejemplo, los jóvenes). Una segunda motivación tendría que ver con las necesidades de la población en materia de servicios. Muchos ayuntamientos habrían visto en los crecimientos la oportunidad de conseguir una población suficiente para obtener servicios que, de otro modo, no podrían llegar a prestar, bien por falta de población, bien por falta de recursos. Esto a menudo conduce al establecimiento de una competencia entre municipios, a fin de tener más crecimiento, para atraer más población y, por tanto, más recursos, más servicios, etc. Otro aspecto de interés para los ayuntamientos sería la obtención de suelo, del que normalmente son deficitarios, para ubicar equipamientos, debido a la cesión que, por ley, se debe hacer de una parte de los terrenos urbanizados.

Pero, a pesar de la mayor o menor influencia de estas circunstancias, hay una cuestión que resulta definitiva: la financiación. Los procesos de urbanización suponen una importante fuente de recursos económicos para los ayuntamientos y, muchas veces, el crecimiento se da por los ingresos que estos obtienen. Este hecho fue reconocido por los propios representantes municipales, que lamentaron la inadecuada financiación de la administración local aunque, en algunos casos, también señalaron los gastos que supone el desarrollo de la urbanización.

El problema de esto es la mala financiación de los ayuntamientos (...). Las licencias de obras suponen una ayuda, es decir, evitan una presión asfixiante sobre las finanzas municipales, pero lo que hacen es ir alargando, y posponiendo, el problema para un futuro, porque con posterioridad, esto conlleva una serie de problemáticas, que es el tema del mantenimiento. Por tanto, es aquel dicho de "pan para hoy, hambre para mañana".

Ayuntamiento de Vilajuïga

Los crecimientos urbanísticos hacen más compleja la gestión municipal, e implican un aumento del gasto, por el mantenimiento de las nuevas zonas urbanas, además de provocar nuevas demandas de servicios. Desde los movimientos vecinales se argumentaba que esta

3 En su momento, Departamento de Política Territorial y Obras Públicas (DPTOP). 
cuestión no es suficientemente valorada por muchos municipios, que no ponderan los posibles perjuicios de los desarrollos urbanísticos, y que entran en una rueda, que aún espolea más el crecimiento.

Conlleva dificultades que inicialmente no se valoran, porque ante un crecimiento tan grande, las necesidades de servicios y de gasto que representa para el municipio, aunque de entrada sea todo a base de recaudación, por lo que suponen las licencias de obras y los impuestos que paga el promotor, al poco tiempo, no mucho, esto se convierte en un gasto desorbitado, si el crecimiento es también desorbitado.

Asociación de Vecinos de Palau-saverdera

Así pues, los ayuntamientos, por las competencias y el grado de autonomía en la materia, son un elemento primordial en los crecimientos ya que son los que, en primera instancia, dan el visto bueno a los procesos de urbanización. Sin embargo, su actuación frecuentemente se encuentra sujeta a las difíciles circunstancias en que desarrollan su actividad, sin una financiación adecuada. A ello se habría añadido la presión ejercida, a menudo, por parte de los agentes privados vinculados al urbanismo, sobre una administración que en ocasiones adolece de una gran debilidad. Por eso muchas veces los ayuntamientos se ven abocados a propiciar una dinámica expansiva de la urbanización. Esta situación se materializa sobre todo en el caso de los municipios menos poblados, que funcionan con una mínima estructura y muy pocos recursos económicos. Además, el posicionamiento frente a los crecimientos con frecuencia depende de aspectos más bien subjetivos, y muy particulares -como el talante de la persona que ocupa la alcaldía o los años que lleve de mandato-; unos aspectos que parecen tener más influencia que, por ejemplo, el color político del Gobierno municipal ${ }^{4}$.

\section{IV.1.2. La Generalitat}

El papel de la Generalitat se consideraba, en las entrevistas, como muy significativo y en general positivo, al menos durante los últimos años del período analizado. La línea de actuación emprendida en ese momento por el Gobierno se veía como algo necesario, y en general se entendía que se intentaban salvaguardar espacios y frenar las dinámicas de ocupación en curso, mediante la activación del programa de planificación territorial. Era desde las plataformas de defensa que se tenía una visión más crítica, ya que se reclamaba una mayor concreción al establecer el marco general en que los municipios deben desarrollar el urbanismo, y un mayor celo al ejercer el control de los ayuntamientos.

Así se señalaba como, tras el cambio de gobierno de 2003, cuando después de veintitrés tres años de mandato de CiU se pasó a un ejecutivo de izquierdas, se produjo un giro importante de las políticas territoriales, que implicó la reanudación de los diferentes planes territoriales, previstos por la Ley de política territorial de 1983, y que en su mayoría no se habían

4 Los cuatro cargos electos que se entrevistaron -en el quinto caso, la persona entrevistada formaba parte del personal técnico- se habían presentado a las elecciones por cuatro formaciones distintas: CiU, PSC, ERC e ICVEUiA. 
realizado. El nuevo rumbo suponía para las entidades cívicas la confirmación de muchos de sus planteamientos, pero también respondía al convencimiento del nuevo Gobierno de la necesidad de controlar y dirigir las dinámicas territoriales, y que para ello se precisan instrumentos de planeamiento supramunicipal.

Nosotros creemos que en el conjunto del territorio de Cataluña, pero, por ejemplo, en el ámbito del Empordà, o más específicamente del Alt Empordà, es del todo necesario tener instrumentos de planeamiento de carácter supramunicipal, porque las dinámicas en este territorio, que tiende a integrarse más y más, son muy difíciles de contrastar sólo con instrumentos de carácter municipal y, por tanto, se necesitan unos instrumentos de otro ámbito.

Oriol Nel·lo. Secretario de Planificación Territorial.

La Generalitat impulsó en ese momento un ambicioso programa de planificación territorial y urbanística de ámbito supramunicipal, con una significativa incidencia en el ámbito de estudio. En primer lugar se aprobaron los dos planes directores urbanísticos del sistema costero (2005). Poco después fue el turno para el Plan Director Territorial del Empordà (2006). Finalmente se afrontó la redacción de los planes directores urbanísticos de la Sierra de Rodes (2006) y del Sistema Urbano de Figueres (2010). Según lo manifestado por Oriol Nel·lo, Secretario de Planificación Territorial, enseguida se quiso actuar en esta zona, como en el resto del litoral catalán, con el Plan Director Urbanístico del Sistema Costero, para detener -en la medida de lo posible- la transformación que se estaba produciendo.

Lo que nos preocupó, de entrada, era cómo incidir en el proceso de transformación del área costera. Por eso, lo que hicimos, tan pronto como tomamos posesión, fue sacar adelante el Plan Director Urbanístico del Sistema Costero, (...) detener, hasta donde fuera posible, en términos legales, el desarrollo urbanístico, sobre todo vinculado a segunda residencia, en los ámbitos costeros.

Oriol Nel·lo. Secretario de Planificación Territorial.

Después de esto se desarrolló el Plan Director Territorial del Empordà, para tratar de ordenar el crecimiento urbanístico del área, dirigiéndolo hacia las localidades más grandes y con mayor capacidad de irradiar servicios -sobre todo la capital, Figueres-, y controlándolo en el resto de poblaciones, y en algún caso -los núcleos más rurales y dispersos-, incluso limitándolo. A su vez, el Plan Director Urbanístico de la Sierra de Rodes pretendía limitar las previsiones de crecimiento existentes en su ámbito de actuación, que proyectaban extensos crecimientos por las pendientes de las sierras de Verdera y de Rodes, mediante la desclasificación de algunos de los sectores de suelo urbanizable. Finalmente, el Plan Director Urbanístico del Sistema Urbano de Figueres pretendía ordenar los crecimientos en el área en que se quería potenciar la implantación urbanística, la ciudad de Figueres y sus alrededores.

La puesta en marcha del programa de planeamiento se valoraba en las entrevistas de manera ciertamente positiva. Se destacaban, por ejemplo, la intención de ordenar el territorio o la voluntad de consenso con las diferentes partes implicadas. Sin embargo, la visión de cada uno de los planes ya era más diversa. Respecto al Plan Director Urbanístico del Sistema 
Costero, la valoración era en general positiva, sobre todo en referencia a su elevada operatividad, puesto que desclasificaba los suelos urbanizables no delimitados, definía un fondo para la gestión de estos espacios, etc. En cambio, la valoración del Plan Director Territorial del Empordà resultaba más rica en matices. Había opiniones positivas, que destacaban los planteamientos realizados, que debían servir para delimitar el marco de los futuros crecimientos, así como el proceso de aprobación, que se realizó con bastante transparencia, y a lo largo del cual se aceptaron muchas de las alegaciones. Entre los críticos, por un lado, había quien lo consideraba demasiado restrictivo, y que limitaba en exceso los crecimientos más allá de Figueres y sus alrededores, por ejemplo los de Roses, uno de los centros turísticos del litoral. También se criticaba el hecho de que no planteara un modelo de desarrollo económico alternativo al turismo. Por contra, había quienes lo criticaban por ser demasiado permisivo. Fue el caso de Salvem l'Empordà; colectivo que había reivindicado insistentemente la redacción de un plan director para la comarca. La representante de la plataforma, aunque reconocía que el plan tenía un cierto valor, explicaba que no había cumplido sus expectativas, y le criticaba la falta de concreción en aspectos como la capacidad de carga del territorio, la gestión del agua o la gestión de los residuos.

Por un lado (...) este plan director está muy bien, porque es un primer paso, que no se había hecho nunca y ha regulado cosas que no se habían regulado nunca. Nunca se le había dicho a un ayuntamiento si puede crecer de esta manera o no. Por tanto, en este sentido, lo valoramos muy positivamente. Pero, por otra parte, no ha cumplido nuestras expectativas, porque hay cosas muy ambiguas y, por tanto, los ayuntamientos podrán acabar aplicándolo un poco como les parezca, y el órgano que deberá poner paz en el tema será la Comisión de Urbanismo.

Plataforma Salvem l'Empordà

Finalmente, más controvertida fue aún la valoración de la Comisión Territorial de Urbanismo de Girona ${ }^{5}$. Este organismo, como el resto de comisiones territoriales, cumple funciones de carácter informativo, consultivo, gestor y resolutivo, y es el encargado de aprobar de forma definitiva los planes de ordenación urbanística municipal y muchas de las figuras de planeamiento urbanístico derivado (planes de mejora urbana, planes parciales urbanísticos, etc.). Pues bien, por un lado hubo voces muy críticas, sobre todo entre el tejido asociativo, desde el que se reclamaba un papel más activo de la Comisión, ya que se consideraba que debería ejercer un control más firme de los desarrollos urbanísticos planteados por los ayuntamientos. Por otro lado, en cambio, hubo personas entrevistadas que, a partir de la actuación de la Comisión en casos concretos, sí que le reconocían un cierto papel de arbitraje y control, poniendo freno e incluso echando para atrás algunos proyectos.

5 Estas valoraciones no se pudieron contrastar con la visión que se tenía desde los Servicios Territoriales de Urbanismo de Girona, ya que la persona entrevistada, que formaba parte de su equipo técnico, no quiso valorar el papel de la Comisión ni del resto de agentes, por lo que la conversación giró, básicamente, alrededor de informaciones de carácter técnico, como la estructura del planeamiento o el estado de tramitación de las diferentes figuras de planificación territorial y/o urbanística. 


\section{IV.2. Las plataformas de defensa y los movimientos vecinales}

A continuación se pondrá la atención en las plataformas de defensa y las entidades vecinales movilizadas a raíz de la intensificación de la presión urbanística. Como se ha dicho antes, en esos años se suceden diferentes procesos de realización efectiva de nuevas áreas urbanizadas, o de formulación de planes urbanísticos para definir futuros crecimientos, que generan un fuerte estallido de conflictividad territorial. Por un lado hay movimientos que actúan con una visión global, no siempre vinculados a posiciones ecologistas, aunque a menudo esta sea la visión que de ellos se tiene, y que tuvieron un gran exponente en Salvem l'Empordà. Por otra parte hay movimientos vecinales que aparecen en municipios concretos, en unas ocasiones articulados en torno a las asociaciones de vecinos y en otras alrededor de nuevas plataformas, constituidas expresamente, y que agrupan bajo su paraguas a otras entidades. En general estas organizaciones compartían la visión de que los crecimientos en curso en esos años se caracterizaban por su gran magnitud, por no haberse realizado de la manera más adecuada y por haberse ejecutado con mucha celeridad, por lo que irrumpen de forma muy repentina en el paisaje.

\section{IV.2.1. Las plataformas de defensa}

A priori, en casi todas las entrevistas se reconocía la labor de las plataformas. De ello se deduce que estas entidades habrían adquirido un cierto crédito, incluso entre aquellos más alejados de sus posiciones. Sin embargo, más allá de estas primeras consideraciones, hubo voces que acabaron mostrando su desacuerdo con la labor de estos movimientos. En las posturas contrarias a estos colectivos se constataba una misma idea: que estas entidades tienden a oponerse a todas las propuestas de cambio y que la suya es una posición muy inmovilista. Esta visión, evidentemente, no era compartida por estos grupos. La portavoz de Salvem l'Empordà argumentaba que ellos casi siempre presentan una alternativa, y que esta visión no denota otra cosa que una cierta estigmatización de estos movimientos.

Esto es una imagen que el que se la inventó, se la inventó muy bien, pero no hay tantos grupos que estén diciendo que no y no presenten una alternativa. (...) Nosotros, (...) no somos la cultura del "no", sino la cultura del "¿por qué?” en contra de la cultura del "sí, señor". Una cosa es decir "sí, señor" a todo lo que dice la Generalitat, y nosotros decimos “¿por qué?”, “¿por qué esto?” y “¿por qué no esto otro?". En cambio, a nosotros, nos encastan en "la cultura del no".

Plataforma Salvem l'Empordà

Otra crítica que se hacía de las plataformas es que tienden a centrarse en unos proyectos concretos, muy evidentes, y que no se muestran tan beligerantes con otras cuestiones, no tan visibles, pero que también tienen su incidencia. El hecho de centrarse en aquellos procesos más llamativos probablemente responda, al margen de otras consideraciones, a la estrategia de realizar actuaciones lo más espectaculares posibles, para llamar la atención de los medios; una cuestión básica para que sus reivindicaciones consigan cierto eco. Sin embargo, a pesar 
de esa búsqueda de la imagen, y del sesgo hacia unos temas determinados -como el golf-, de la mayoría de las entrevistas se desprendía una valoración positiva, ya que la gente ve a las plataformas como un elemento necesario, frente a otros criterios de intervención, de carácter más mercantilista.

El caso de Salvem l'Emporda es el más emblemático ${ }^{6}$. El origen de la plataforma se encuentra en la IAEDEN (Institución Altempordanesa para el Estudio y la Defensa de la Naturaleza) que había surgido a partir de las movilizaciones para la protección de los humedales del Empordà, desarrolladas en los años setenta, y que acabaron con la declaración del Parque Natural de los Aiguamolls del l'Alt Empordà, en 1983. El detonante de la constitución de Salvem fue el gran número de proyectos urbanísticos planteados en la comarca en el cambio de siglo. La IAEDEN convocó a la ciudadanía a una reunión para debatir sobre el futuro del territorio. La llamada fue un éxito, y de aquella reunión surgió una plataforma cívica, que aparecía con una única meta: la defensa del territorio. El hecho de focalizar todos los esfuerzos en este objetivo hizo que mucha gente, y gente muy diversa, se implicara. Además del posicionamiento contra cada proyecto, se pedía la redacción de un plan director para la comarca, que mientras se redactase dicho plan se decretara una moratoria urbanística y que el plan fuera elaborado bajo los principios de sostenibilidad, equilibrio territorial y participación.

En algunas entrevistas se criticaba de este colectivo que aquellos que lo forman, en realidad, no son gente de la comarca, sino personas foráneas, que hace poco que viven allí, o que sólo tienen en ella una segunda residencia. Esta percepción tal vez se pueda relacionar con el hecho de que es la gente que ha ido a estudiar fuera, cuando vuelve, la que más participa, mientras que la gente más joven, por debajo de la treintena, no se implica tanto. De todas maneras, también se recogió un buen número de manifestaciones que sí otorgaban a Salvem l'Empordà una elevada representatividad, y que permiten constatar cómo su trabajo de voluntariado disfrutaría de bastante prestigio entre la gente del territorio. Una visión positiva que incluso se reflejaba en las manifestaciones del representante del Gremio de Promotores, cuando señalaba que, aunque desde una óptica muy diferente, se podían encontrar coincidencias entre ellos y las plataformas como Salvem: por ejemplo, en la demanda a las administraciones para que definan unas reglas más claras en relación a los crecimientos.

En muchos debates en los que participo, en los que está Salvem l'Empordà, nos ponemos siempre de acuerdo. Es decir, estoy absolutamente de acuerdo en que probablemente hay muchos planeamientos que no responden a la realidad actual. Vosotros pedís que se revisen y yo también, como asociación de promotores, por la necesaria seguridad jurídica que nosotros quisiéramos.

Gremio de Promotores y Constructores de Edificios de Girona

De las entrevistas se extrae que el papel de las plataformas es el de generar opinión, y sacar a la luz unos proyectos que seguramente no habrían llegado a trascender, al menos en

$6 \quad$ El nombre de Salvem hizo fortuna, ya que después fue utilizado por muchas otras organizaciones de la comarca y en toda Cataluña. Algunos ejemplos, y sin ánimo de ser exhaustivo, serían los de Salvem la Garriga i Pla Vinyers, Salvem el Crit, Salvem Castell, Salvem Pinya de Rosa, Salvem les Guilleries, Salvem les Valls y Salvem el Penedès. 
los niveles en que finalmente lo hicieron. No es que la información no sea pública, pero no es fácilmente accesible, y estos colectivos la dan a conocer. Además de esta tarea de concienciación, las plataformas terminan ejerciendo una cierta labor de control de la administración, respecto a estas cuestiones. Por todo ello resulta tan importante la relación entre estas organizaciones y los medios de comunicación, que actúan de amplificador de sus reivindicaciones. Finalmente, al margen del papel en el caso de algunos proyectos concretos, la actuación de las plataformas sirvió para propiciar el desarrollo de la planificación territorial y supramunicipal, ya que pese a que detrás de las actuaciones de la Generalitat en este período había toda una filosofía, las movilizaciones ciudadanas contribuyeron a la puesta en marcha y la aceleración de los diferentes planes realizados en el área.

\section{IV.2.2. Los movimientos vecinales}

En las entrevistas se constataba una visión ciertamente positiva de estos colectivos, por la novedad que supone la movilización de unas personas, en principio, no vinculadas ni a partidos políticos ni a entidades conservacionistas. Estas entidades locales intentan incidir en las administraciones municipales, oponiéndose a proyectos concretos, o posicionándose en contra de los planteamientos de los planes de ordenación urbana municipal. Estas organizaciones se erigen en interlocutoras de buena parte de la ciudadanía, estableciendo una negociación con el Ayuntamiento, al que acaban trasladando una serie de propuestas de modificación de lo inicialmente planteado. Para poder desarrollar esta función, es importante el papel de los medios de comunicación, que tienen una gran incidencia, incluso en estos ámbitos más locales.

No obstante, también se pudieron recoger algunas consideraciones no tan favorables, que entendían que estas movilizaciones, en el fondo, responden a motivaciones individuales y que persiguen intereses estrictamente particulares. Ahora bien, también había quien no consideraba esto como un problema, sino como una muestra de participación e implicación ciudadana. Desde estos grupos se reconocía que las motivaciones individuales tal vez fueran el detonante de la movilización, pero que después, una vez iniciadas las acciones, ya inciden aspectos de carácter más general.

Yo me moví por una cuestión particular, los primeros quince días, porque lo primero que quería solucionar era lo que tenía delante de casa (...). No pasa nada por decir que me muevo por una cuestión particular, porque también tengo el derecho de moverme para defender lo que yo puedo considerar que son mis intereses. (...) siempre que se explique bien y se sepa. Lo que pasa es que, después, levantas la cabeza y dices: (...) no es sólo mi pueblo, sino que es toda la comarca...

Plataforma Cívica contra la Construcción Masiva de Castelló d’Empúries

Las similitudes y divergencias entre estas entidades locales y las organizaciones de ámbito más general constituyeron otro de los elementos de análisis. Desde el punto de vista de Salvem l'Empordà, organización referente para muchos de estos grupos, se entraría en contacto con las organizaciones vecinales de los distintos municipios, para coordinarse con ellos. 
Normalmente, en los pueblos donde se generan conflictos, se crea un grupo de trabajo del pueblo, integrado por algunos vecinos que se agrupan, y, más o menos, estamos en contacto. Por ejemplo, un caso sería el de Castelló. Ahora se está revisando el POUM, y todo un grupo de vecinos se han puesto a trabajar. Nosotros estamos en contacto, pero somos entidades diferentes, aunque estamos más o menos coordinados en una estrategia conjunta.

Plataforma Salvem l'Empordà

Para la mayoría de los movimientos vecinales, Salvem supone un refuerzo importante, que les puede ayudar en sus acciones, pero sobre todo constituye el marco general en el que encuadrar sus reivindicaciones. En algunos casos, sin embargo, lo que se busca es más bien una cierta complementariedad, ya que entre las dos organizaciones (la comarcal y la municipal) no siempre hay una coincidencia absoluta. Esta falta de coincidencia en algunos temas puede hacer que a estos grupos a veces les interese desmarcarse de las organizaciones como Salvem, por la visión que se ha tenido de ellas, como movimientos eminentemente ecologistas. A veces estos grupos se definen a sí mismos como más proclives a llegar a acuerdos con la administración local, con el ánimo de buscar una solución consensuada, dentro de su ámbito en concreto.

\section{IV.3. Los agentes privados vinculados a la actividad urbanística}

En este punto hay que centrarse en el análisis de los agentes privados vinculados al urbanismo. Por un lado se hallan los propietarios del suelo, que tienen la titularidad de los terrenos no urbanos, tanto de los urbanizables, que se convierten en urbanos cuando se inicia un proceso de urbanización, como de los no urbanizables, que pueden pasar a ser urbanizables con una revisión del planeamiento. Por otro lado se encuentran los promotores inmobiliarios, que son los empresarios que, a partir de un capital mobiliario -de su propiedad o de otros-, impulsan la construcción de edificios, con el objetivo de sacar la máxima rentabilidad. Finalmente, los constructores son los industriales que, contratados por los promotores, llevan a cabo la ejecución de la obra. Dada la interdependencia entre promotores y constructores, y el hecho de que en muchos casos coinciden, se tratarán aquí de forma unificada, y se hablará, en genérico, de los promotores inmobiliarios.

\section{IV.3.1. Los propietarios de suelo}

En el área analizada existían tradicionalmente unos grandes propietarios de la tierra, en su mayoría absentistas, que aglutinaban fincas de diferentes poblaciones, y que residían en el territorio pero también en Girona o Barcelona. Este modelo aún persiste, aunque ciertamente diluido, a través de las sucesivas herencias y transmisiones patrimoniales. De hecho, la mayoría de voces consideraban que este modelo, que propició las grandes operaciones de los años sesenta y setenta, a raíz del turismo, habría agotado hoy su capacidad de condicionar 
los procesos de urbanización ${ }^{7}$, puesto que en este período (1996-2006) las operaciones se habrían realizado a partir de la adición de pequeñas propiedades, que se aglutinan a través de una serie de transacciones, y que están más en función de la clasificación del suelo definida en el planeamiento que de la propiedad de la tierra y la parcelación agrícola.

Por otra parte, parece que el esquema de un agricultor que, ante la tesitura de dejar de trabajar el campo o continuar su labor, decide vender y cesar su actividad, hay veces que sí que se produce. Pero, al mismo tiempo, cada vez es más habitual que los propietarios de los terrenos susceptibles de ser urbanizados ya no formen parte de la propiedad agrícola, sino que sean grupos de inversores que, con los cuantiosos capitales facilitados por el sector financiero en este período, habrían ido comprando terrenos a los pequeños propietarios, a bajo precio, para ir aglutinando tierras de cara a futuras posibilidades de negocio.

La propiedad agrícola, en los últimos diez años, ha cambiado quince veces de manos; (...). en todos los terrenos que son urbanizables, o que podrían serlo en futuras revisiones, porque tienen aptitudes y porque están al lado de lugares por donde es lógico que el crecimiento urbano extienda la ciudad, el campesino ya hace muchos años que no es el propietario.

Colegio de Arquitectos. Delegación del Alt Empordà

En todo caso, el papel de los propietarios de suelo suele ser el de esperar a que llegue la oferta de un promotor que quiera urbanizar sus terrenos, puesto que así es como maximizan beneficios. Esta parece ser la estrategia más habitual, más que sacar adelante las promociones por sí mismos; una dinámica más habitual durante el desarrollo turístico de los sesenta y setenta. En estos procesos, la capacidad de negociación de la pequeña propiedad es muy limitada, ya que si no se aviene a un acuerdo, el proyecto puede salir adelante sin su participación. Esta situación no se da, en cambio, cuando el terreno ocupa una posición muy central en la futura urbanización, ya que en ese caso se intenta incluirlo, a cualquier precio.

No siempre la adquisición de suelo se hace para urbanizarlo de forma inmediata, sino que a veces los terrenos son comprados por grupos de inversores, a la espera de futuras posibilidades. Parece que estos procesos de compra-venta de terrenos susceptibles de ser urbanizados habrían supuesto un muy buen negocio durante esos años; una circunstancia que hizo que estas operaciones se fueran haciendo una y otra vez, contribuyendo al encarecimiento del suelo y al alza del precio de la vivienda.

Y sucede mucho en las parcelas de estas grandes unidades de actuación, en las que se deben hacer veinte, cuarenta o sesenta viviendas adosadas. En concreto, hay una cerca del río, que ha pasado por cinco manos diferentes. Se van revendiendo, y los precios van subiendo, van subiendo... Hay muchas operaciones de especulación...

Ayuntamiento de Sant Pere Pescador

7 No se pudo contrastar esta visión con el Instituto Agrícola Catalán de Sant Isidre, la patronal que tradicionalmente ha aglutinado a los grandes propietarios agrarios, ya que desde la institución se desestimó la invitación a participar en este estudio. 


\section{IV.3.2. Los promotores inmobiliarios}

La relación entre promotores y ayuntamientos resulta muy importante en este período. Por ello, un primer aspecto a valorar fue la visión de los promotores por parte de los representantes municipales. Se pudo constatar, así, que los ayuntamientos ven a los promotores como un agente que ejerce un papel significativo, pero no determinante. En esta línea los representantes municipales argumentaban que, aunque estos empresarios, con su actividad, buscan obtener un beneficio, este hecho no tiene porque ser negativo y que, en todo caso, si de su actuación se derivan ciertos perjuicios, no les corresponde a ellos dirimirlo, sino que le corresponde a la Generalitat.

El promotor juega un papel importante, lo que pasa es que el promotor quiere ganar dinero, (...) porque es un negocio, (...). Nuestra misión no es ni hacer que los demás ganen ni que no ganen dinero, nosotros tenemos que mirar que el pueblo quede bien, y el dinero que ganan es problema suyo y, en todo caso, no es problema nuestro, es un problema de más arriba.

Ayuntamiento de Torroella de Fluvià

En el resto de entrevistas, el grado de responsabilidad de los promotores en los crecimientos urbanísticos resultaba ser una cuestión ciertamente controvertida. En el caso de los profesionales que intervienen en el sector del urbanismo, por una parte se consideraba que los promotores son un agente activo, que ejerce cierta presión sobre los ayuntamientos, a fin de satisfacer sus intereses económicos. Pero por otra parte había posturas que situaban a los promotores como un agente más bien estático, que se ve forzado a reclamar seguridad jurídica ante los posibles conflictos que a veces estallan a raíz de los procesos de urbanización. En lo que se refiere al empresariado turístico, por un lado ser recogían voces que otorgaban una mayor responsabilidad a las administraciones, al considerar que los promotores se dedican, simplemente, a desarrollar su actividad empresarial. Por otro lado, en cambio, había posturas que también exponían las presiones que, a menudo, los promotores aplican sobre los ayuntamientos. En el caso del sector agrario, en unos casos se eximía a los promotores de buena parte de la responsabilidad, porque lo que hacen es llevar a cabo su actividad económica, hasta el límite que les permite la normativa. En otros casos, sin embargo, se mantenía una postura más crítica, al considerar que los promotores obtienen pingües beneficios a costa de ocasionar un fuerte impacto sobre el territorio. Esta controversia se daba incluso en el caso de las entidades. En este sentido, se podían encontrar ciertas coincidencias entre los representantes de las plataformas y los promotores, en cuanto a la reclamación de una mayor y más clara reglamentación de los crecimientos. De todos modos, también se recogía una visión más crítica, en el sentido de que los promotores se aprovechan de las circunstancias de falta de recursos económicos y técnicos de muchos ayuntamientos.

También se analizó el papel de los promotores en el encarecimiento de los precios de la vivienda. Los promotores, como es lógico, defendían su papel, argumentando que durante este período lo que se habría encarecido, en realidad, habría sido el precio del suelo, y que, por ello, los precios de la vivienda se ven determinados más por la vivienda de segunda 
mano que por la obra nueva. De esta manera, los promotores inmobiliarios atribuían la responsabilidad del alza de precios al conjunto de la sociedad.

Con este boom, ¿quién pone los precios del mercado? Los ciudadanos que se revenden el piso, y ¿por qué? Porque en las ciudades (...) en el centro no se pueden hacer viviendas, ya no hay suelo; por lo tanto, si alguien tiene un piso y se lo vende, puede poner el precio que quiera. Lo venderá más o menos rápido, pero lo acabará vendiendo, porque habrá alguien que querrá vivir allí, (...) Y esto es una espiral imparable. Por tanto, los precios del mercado, (...) los pone tanto o más la segunda mano que la primera.

Gremio de Promotores y Constructores de Edificios de Girona

En el resto de entrevistas, de nuevo las posturas al respecto resultaban divergentes. En el caso, por ejemplo, de los profesionales relacionados con el urbanismo, mientras que por un lado se señalaba que los promotores habrían contribuido a la escalada de precios, encareciendo sus promociones, ante la fuerte demanda del momento, por otra parte se argumentaba que los gastos a los que deben hacer frente (precio del suelo, costes de urbanización y cesiones) resultan ciertamente elevados, y que esto se traduce en un encarecimiento del producto final.

Otra de las cuestiones que se trataron fue el hecho de que los promotores desempeñan su actividad con unas ópticas de actuación y en unos mercados cada vez más generales. Este hecho incide en la proliferación en este ámbito de promociones desarrolladas por promotores foráneos; circunstancia que hasta ese momento no se había dado, al menos con la intensidad en que lo hizo en ese período. En esta línea, se habría producido el desembarco en esta área, como en muchas otras, del gran capital cada vez más globalizado, que habría ido sustituyendo al promotor más local. La llegada de grandes grupos inmobiliarios de Barcelona, o de otras partes de España, e incluso de algunos que operan en ámbitos internacionales, era reconocida por el representante del Gremio de Promotores de Girona.

Llega un momento en que, a nuestras ciudades, llega gente de Barcelona... y del resto de España, y los promotores de tipo medio se trasladan a las áreas urbanas y los promotores locales se trasladan... (...) a nosotros ahora ya no nos da miedo ir a un pueblo pequeño, como a los de Madrid no les da miedo ir a una zona desconocida. Es el mercado global; y el que no se ha adaptado a ello ha tenido problemas. Es decir, el promotor local que se quería mover sólo en el ámbito local ha quedado desbordado por todo: por la dinámica, por las tipologías, por los precios...

Gremio de Promotores y Constructores de Edificios de Girona

El desembarco de las grandes promotoras se habría producido por varios motivos: el propio dinamismo del mercado inmobiliario gerundense, el excesivo encarecimiento del suelo en otras zonas más centrales y el potencial de crecimiento relacionado, por ejemplo, con la llegada del AVE. La irrupción de estas grandes empresas habría incidido en el encarecimiento de los precios, en el aumento de la magnitud de las operaciones y en el cambio de 
las configuraciones urbanísticas y edificatorias, con la implantación en los pequeños núcleos rurales del ámbito de tipologías hasta entonces ajenas, como las promociones con zonas comunitarias ajardinadas y piscina o los bloques de pisos. Finalmente, esta tendencia habría comportado la pérdida de negocio de las pequeñas empresas locales, que redundaba en un cierto beneficio para la población del área, en forma de creación de actividad económica o generación de puestos de trabajo, y que de esta manera se habría visto reducido.

\section{IV.4. Los sectores económicos tradicionalmente relevantes}

El inventario de los agentes concluye con los dos sectores económicos tradicionalmente más representativos del área: el sector turístico y el agropecuario. El empresariado turístico, muy relacionado con los desarrollos urbanísticos de los sesenta y setenta, en este período habría comenzado a observar los crecimientos con cierta preocupación, al verlos incompatibles con el producto turístico que quieren ofrecer. El papel del campesinado (agricultores y ganaderos) estaría muy ligado al de los propietarios de suelo, ya que a menudo son los que tienen la titularidad de los terrenos no urbanos, aunque con una capacidad de incidencia muy limitada, debido a las difíciles circunstancias por las que atraviesa el sector.

\section{IV.4.1. El empresariado turístico}

Algunos representantes del sector señalaban que la proliferación de la urbanización, llegada a un cierto punto, resulta contraproducente para su actividad, ya que puede dañar el paisaje, que es el verdadero atractivo de la zona. Sin embargo, también había quien manifestaba que la construcción había sido el motor de la economía, y que no sería conveniente detenerla si primero no se encontraban alternativas, para que el sector pudiera continuar con su dinamismo. Por eso se argumentaba que era necesario encontrar un punto intermedio, entre crecimiento urbanístico y preservación del medio. Esta dicotomía se reproducía al valorar el papel de la segunda residencia. Por un lado se manifestaba que las segundas residencias, si no forman parte de la oferta reglada, poco tienen que ver con el turismo. En la misma línea, se consideraba que el valor económico de la segunda residencia resulta bastante inferior al de la infraestructura hotelera, ya que la segunda residencia genera riqueza sólo cuando se construye, mientras que la infraestructura hotelera permite obtener beneficios continuados, además de generar más empleo. No obstante, había quien tenía una visión más positiva del turismo residencial, al considerar que las segundas residencias, al fin y al cabo, no dejan de ser una fuente de clientes para la hostelería y sobre todo la restauración.

Por tanto, se habría modificado -al menos en parte- la visión de los desarrollos urbanísticos y de la segunda residencia por parte del empresariado turístico, en relación con las transformaciones de orden general experimentadas por el turismo en el cambio de siglo, en la línea de una mayor singularización y mejora de la oferta. Así, en la zona analizada se habrían producido cambios significativos en la infraestructura de alojamiento, con un cierto crecimiento de la oferta, pero sobre todo con la reestructuración de la misma. Se simultanean la disminución de plazas en las grandes poblaciones costeras, y la apertura 
de pequeños hoteles con encanto y de turismo rural en las localidades más pequeñas y del interior. Además, se habría producido una mejora y adecuación de las instalaciones, a fin de satisfacer una demanda cada vez más exigente.

Están experimentando ciertas variaciones las tipologías de los establecimientos hoteleros: antes, en un hotel, mientras tuvieras una habitación, y poco más, ya hacías. Hoy en día exiges muchos más servicios, para poder hacer estas mismas actividades en el hotel, o fuera del hotel, las consumirás o no, pero a la hora de plantearte buscar un hotel, te planteas que tenga muchas más cosas.

Patronato de Turismo Costa Brava Girona

Los períodos vacacionales varían, y también las estancias de los turistas, que antes se extendían todo el verano, pero se concentraban únicamente en esta temporada. Ahora, en cambio, las vacaciones se acortan, se fragmentan y se diversifican, por lo que también resultan importantes las ocupaciones en otros períodos, como los fines de semana o los puentes. Esta fragmentación de las estancias, en el caso de los turistas norte-europeos, habría sido facilitada por las operaciones de Ryanair en el aeropuerto de Girona, que han incidido en el aumento del volumen de pasajeros de la infraestructura. Otro aspecto al que se aludía, cuando se hacía referencia a la evolución del turismo, es el aumento del peso de los nuevos productos turísticos, que se nutren de atractivos distintos del sol y playa, y que se pueden ejemplificar con el reclamo que suponen los recursos históricos, artísticos y culturales de la villa condal de Castelló d’Empúries o los valores naturales del Parque Natural de los Aiguamolls. Ahora bien, más que en un sustitutivo de las playas, estas ofertas se habrían convertido en un elemento complementario que, además de incidir en la frecuentación del interior, ayuda a mantener los niveles de ocupación de la costa en verano, y contribuye a incrementarla en otros momentos del año.

El sector ha tenido que ser cada día más imaginativo, para atraer a la clientela: senderismo, submarinismo, hípica, golf... Para atraer a un cierto número de clientes, que pueda solucionar, como mínimo, la ocupación en los meses de temporada baja. Todo esto tiene que funcionar, no basta con el sol y playa, porque el sol y playa son tres semanas en el pico del verano, pero luego tienes que espabilar.

Asociación de Empresarios de Actividades de Hostelería del Alt Empordà

Otra de las cuestiones a valorar es la posible competencia que supone la oferta de otros países de la cuenca mediterránea o de otras latitudes. En este sentido, las personas entrevistadas señalaban que los llamados países terceros no suponen una competencia efectiva, ya que la oferta turística en Cataluña cuenta con el valor añadido de unos componentes de seguridad y de sanidad muy similares a los de los países de origen de los turistas, además de toda una serie de recursos complementarios al sol y playa. En cambio, lo que sí supondría una cierta amenaza es la competencia de las otras regiones del litoral mediterráneo español, que en los años analizados habrían desarrollado productos turísticos mucho más adaptados a las nuevas demandas del turismo vacacional de sol y playa -más equipamientos 
y una mayor oferta complementaria de carácter comercial, de restauración, deportiva, de salud, etc.--, mientras que la oferta de la Costa Brava parece evolucionar hacia un turismo de más calidad, pero más restringido, de estancias mucho más cortas y diversificadas.

\section{IV.4.2. El campesinado}

Los integrantes del sector agrario manifestaban que el rol del campesinado en los procesos de urbanización es un papel muy pasivo, ya que los agricultores y ganaderos son un elemento muchas veces presente, como propietarios de los terrenos donde se desarrolla la urbanización, pero sin prácticamente posibilidades de condicionar el proceso. Desde otras instancias se compartía esta manera de ver las cosas, y además se consideraba que el papel de los propietarios agrícolas está muy condicionado por las circunstancias que los rodean, que hacen que a menudo la venta de los terrenos sea la única alternativa. Sin embargo, también se pudo constatar otra visión del sector, fundamentada en la poca oposición que suelen presentar los agricultores y ganaderos ante los cambios de usos, y en el hecho de que enseguida se avienen a las transacciones. Esto se puede relacionar, en cierto modo, con lo expresado por el propio campesinado, en el sentido que ellos no suelen discutir la ubicación de los futuros crecimientos.

Nosotros, como sindicato agrario, siempre nos metemos con el suelo no urbanizable. Hombre, sí, podemos discutir si hay un crecimiento exagerado, si proponen un crecimiento muy exagerado sobre el no urbanizable, pero nosotros no nos meteremos nunca en si la línea tiene que ir por ahí o tiene que ir a coger la otra parcela.

Unió de Pagesos. Delegación del Alt Empordà

Las difíciles circunstancias del campesinado hacen que éste se encuentre en una clara situación de debilidad. Una situación que contrasta con la capacidad de influencia que el sector y, más concretamente, los grandes propietarios agrícolas habían tenido en el pasado. El sector agropecuario se encuentra hoy muy condicionado por la persistente disminución de la población activa agraria. Esta reducción, aunque se da en todas las actividades, es especialmente relevante en el caso de algunas de las más presentes en el área de estudio, como el sector lechero. Las causas de este descenso se pueden encontrar en la falta de rentabilidad (más aún si se tiene en cuenta el tiempo dedicado), que se ve agravada por las propias incertidumbres del sector (estar a expensas de la climatología) y en el hecho de ser un trabajo muy ligado (sobre todo las explotaciones ganaderas), al que hay que dedicar fines de semana y períodos vacacionales, así como en la falta de perspectivas de continuidad de la explotación, al no haber relevo generacional. La falta de rentabilidad propicia que el campesinado tenga que recurrir a la pluriactividad, para complementar sus rentas, y que los agricultores y ganaderos se conviertan en prestadores de servicios, tanto dentro del sector-llevando tierras de otros- como fuera de éste. Muchas veces los rendimientos de la explotación ya no suponen la parte mayoritaria de los ingresos y son las otras tareas las que permiten continuar la actividad. En otros casos la explotación se mantiene gracias a la agricultura a tiempo parcial, que se ejerce a ratos, los fines de semana, o cuando la persona ya está jubilada. Cuando la ocupa- 
ción complementaria se encuentra fuera del sector, las actividades pueden ser muy diversas, pero en una zona como esta, caracterizada en el período analizado por el fuerte dinamismo de la construcción, destacan la obra pública y la jardinería.

Ante estas circunstancias, las de un sector en el que las personas ocupadas son cada vez menos, y los agricultores y ganaderos que van quedando cada vez más tienen que realizar trabajos complementarios, para compensar la baja rentabilidad, y también ante la falta de continuidad, parece difícil que cuando llegue una oferta de compra no se acabe aceptando, y más si se tiene en cuenta la gran diferencia que hay entre los rendimientos agrarios y los precios que se pagan por los terrenos susceptibles de ser urbanizados.

El campesinado sufre sobre su territorio toda la presión, (...) pero a quien le toca le salva la vida. (...) Hay pocos casos de gente que tenga ofertas que no venda. Aquí, en Castelló, ha habido últimamente dos que han sido, francamente, para sacarse el sombrero. Y uno lo dice a nivel ético, sin embargo, a nivel económico, si no ha vendido, ahora ya, hasta dentro de veinte años que volverá a haber otro plan de ordenación, difícilmente podrá hacerlo; (...) Si uno tiene opción de vender, vende, por supuesto.

Asociación de Agricultores y Cortalers de Castelló d'Empúries

\section{CONCLUSIONES}

A lo largo de estas páginas se ha repasado el papel desempeñado por los diferentes agentes que intervienen en la dinámica urbanística y territorial durante los años del boom inmobiliario (1996-2006) en la llanura del Alt Empordà (Girona). A partir de las entrevistas a portavoces de diferentes colectivos y organizaciones, se ha hecho el repaso de la motivación, vinculación, actuación y grado de responsabilidad de las administraciones públicas, de las plataformas de defensa y los movimientos vecinales, de los agentes privados vinculados a la actividad urbanística y de los sectores económicos tradicionalmente relevantes en el área.

En primer lugar, se ha podido ver como la conjunción entre el papel tan activo de los agentes privados vinculados al urbanismo - propietarios del suelo y, sobre todo, promotores-, y la postura muy receptiva por parte de los ayuntamientos se encuentra en buena parte en el fondo de la aparición de los crecimientos urbanísticos. Los crecimientos han servido para satisfacer los intereses de ambos agentes, ya que los promotores han podido maximizar sus beneficios y los ayuntamientos han podido disfrutar de más recursos económicos, u obtener suelo, por ejemplo, para ubicar equipamientos. En este contexto, diferentes voces han reclamado un papel más activo de la Generalitat, a través de los diferentes organismos e instrumentos a su disposición (planeamiento, comisiones territoriales, etc.), en relación a unos procesos que sobrepasan los ámbitos estrictamente municipales.

En un segundo nivel de incidencia se sitúa el resto de agentes: entidades ciudadanas y sectores económicos tradicionales. Las entidades habrían ejercido una encomiable labor de control de las administraciones, consiguiendo la retirada o la modificación de algunos de los proyectos planteados por el binomio ayuntamientos-promotores. El sector turístico y la agricultura, en cambio, parecen perder parte de su rol preponderante, y se ven desplazados por los agentes privados vinculados a la actividad urbanística. Esta circunstancia se observa 
especialmente en el caso del campesinado, que se convierte en un elemento poco relevante puesto que, dada la difícil situación del sector, se ve prácticamente abocado a vender. El empresariado turístico, por su parte, intenta desmarcarse de la cuestión de los crecimientos, porque pueden llegar a dañar el paisaje, aunque también hay empresarios que ven como satisfactoria la convivencia entre desarrollo inmobiliario y turismo.

En definitiva, la interrelación del papel de todos estos agentes (ver Tabla 2), que está en función de sus ámbitos de actuación, competencias e intereses, habría condicionado la dinámica territorial y urbanística del área de estudio, haciendo que municipios con localizaciones, condiciones y características similares, incluso colindantes, en unos casos hayan crecido, con unas magnitudes y unas tipologías muy determinadas, y en otros, en cambio, se hayan mantenido más salvaguardados. Las actuaciones de cada uno de estos agentes pueden resultar legítimas desde su punto de vista. Sin embargo, la conjunción de todas ellas puede ocasionar efectos no deseados en el plano colectivo (ocupación del suelo, impactos sobre el paisaje, problemas con la movilidad, dificultades para la provisión de servicios, encarecimiento de la vivienda, problemas de accesibilidad a la misma, etc.). Se hace necesaria, por tanto, una mayor regulación y un mayor control por parte de los poderes públicos, de los contextos y las dinámicas en que se toman estas decisiones, a fin de evitar los posibles efectos negativos derivados del libre albedrío. Es por ello que, probablemente, la responsabilidad recaiga en mayor medida en las administraciones. Sin embargo, en el caso de la administración local, tiene que ejercer sus funciones sin una financiación adecuada, y sin los suficientes recursos técnicos, para gestionar con eficacia unas dinámicas que se desarrollan en unos ámbitos que cada vez más sobrepasan su ámbito de actuación, y que se tuvieron que afrontar, durante este período, sin la referencia de la planificación territorial. Asimismo, no hay que olvidar como los agentes privados (promotores y propietarios de suelo) en esos años, dadas las elevadas oportunidades de negocio, llevan su actividad al extremo, y como ello contribuye, en gran medida, a la situación generada. Además, el cambio de escala experimentado por el sector inmobiliario hace que las relaciones entre promotores y ayuntamientos se den en un contexto de creciente desigualdad, incidiendo en las mayores dificultades de los pequeños consistorios locales para gestionar las presiones de estos agentes privados, a menudo foráneos y cada vez más globalizados. La Generalitat se revela en ese momento como el agente que intenta ordenar las dinámicas de urbanización, a través de extender la planificación territorial al conjunto de Cataluña. Se trata de un intento muy loable de establecer las estrategias generales de desarrollo, y no dejarlo sólo a expensas de los designios del libre mercado. Ahora bien, los diversos planes se concluyen con el boom inmobiliario ya terminado, y con un escenario diametralmente opuesto al de unos años antes. A ello se une la incertidumbre derivada de la crisis, y de las políticas de contención del gasto público, que no contribuyen al adecuado desarrollo de la planificación.

Hasta aquí el análisis del papel de los agentes durante los años del boom inmobiliario en la llanura del Alt Empordà, que ha permitido ver cómo todos ellos habrían jugado su papel en mayor o menor medida, según las diferentes visiones, intereses y maneras de proceder. Quizás el avance en el esclarecimiento de esta cuestión pueda ser de utilidad, además de para dar luz a los acontecimientos de un período tan determinante para la evolución económica, urbanística y territorial de nuestro país, también en la actualidad, cuando unos se sirven de los datos macroeconómicos para afirmar que la crisis ya es cosa del pasado, mientras que 


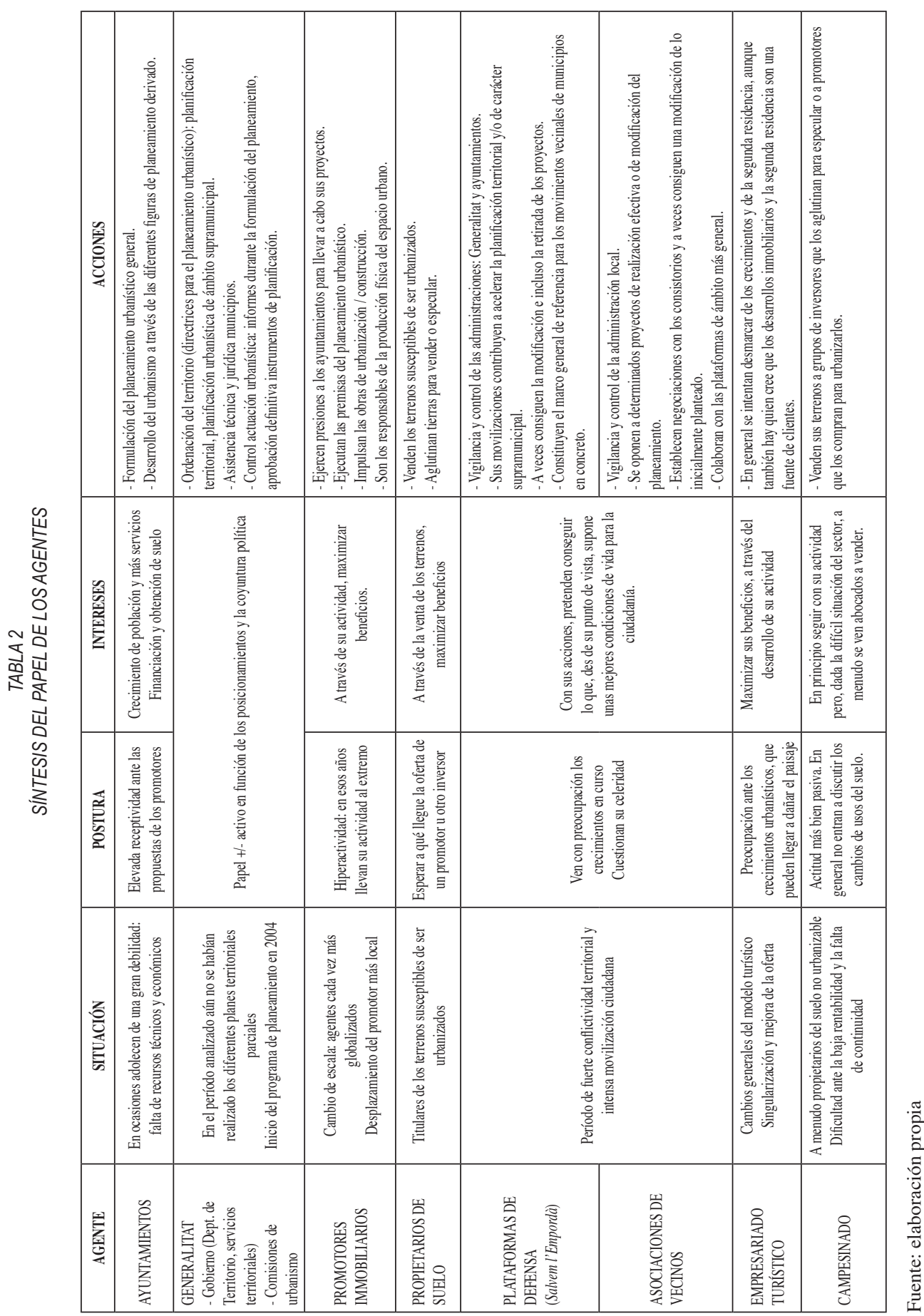


otros constatan como las desgraciadas consecuencias del retroceso económico (aumento de la desigualdad, incremento de la pobreza, elevadas cifras de desempleo, etc.) siguen vigentes, y cuando la recuperación de las cifras de la construcción hace temer que se puedan volver a repetir los errores de aquel período.

\section{BIBLIOGRAFÍA}

AAVV (1978): Debat Costa Brava. Girona. Cambra de comerç i indústria.

BARBAZA, Y. (1981): El paisatge humà de la Costa Brava. Barcelona. Edicions 62.

BERNARDOS, G. (2009): "Creación y destrucción de la burbuja inmobiliaria en España". ICE, $\mathrm{n}^{\circ} 850,23-40$.

BOIXADER, J. (2005): “La acción colectiva de los agentes urbanos en la transformación de Barcelona: aproximación al distrito 22@Barcelona”. Scripta Nova, vol. IX, no 194 (80), 1 de agosto de 2005. Universidad de Barcelona. Disponible en http://www.ub.edu/geocrit/sn/ sn-194-80.htm.

BRETON, F. y ROMAGOSA, F. (2002): “L'evolució dels principals usos del sòl (1957-1994) a través de la fotografia aèria” en Canvis socioambientals a l'Alt Empordà (1950-2000) (Ribas, A. y Saurí, D., Eds.) Girona, UdG, 191-200.

BURRIEL, E. (2008): “La 'década prodigiosa' del urbanismo español (1997-2006)”. Scripta Nova, vol. XII, núm. 270 (64), 1 de agosto de 2008. Universidad de Barcelona. Disponible en http://www.ub.edu/geocrit/sn/sn-270/sn-270-64.htm.

CALS, J. (1982): La Costa Brava i el turisme. Barcelona. Kapel.

CALS, J. (1987): L'Alt Empordà. Recursos i estructura econòmica. Barcelona. Caixa d'Estalvis de Catalunya.

CALS, J. (2005): "Debat final (conclusions generals)", en Debat Costa Brava. Congrés: Un futur sostenible. Girona, COAC, 374-379.

CAPEL, H. (1974): “Agentes y estrategias en la producción del espacio urbano español”. Revista de Geografía, no 8 (1-2), 19-56.

CAPEL, H. (2005): El modelo Barcelona: un examen crítico. Barcelona. Ediciones del Serbal.

CAPEL, H. (2013): La morfología de las ciudades. Agentes urbanos y mercado inmobiliario. Barcelona. Ediciones del Serbal.

COL·LEGI D'ARQUITECTES DE CATALUNYA (COAC) (2005): Debat Costa Brava. Congrés: Un futur sostenible. Girona. COAC.

CRUZ, H. (2006): "Los conflictos urbanísticos: sus causas y sus protagonistas. Una reflexión a partir de la experiencia de Cataluña". Cuadernos de Geografía, n 80, 183-194.

CUADRADO, S. (2008): "Les pressions urbanístiques recents a la plana de l'Alt Empordà i l'actuació de la Generalitat". Annals de l'Institut d'Estudis Empordanesos, n 39, 479497.

CUADRADO, S. (2012): La metropolitanització a la plana de l'Alt Empordà. Exemple d'un nou model territorial a Catalunya. Bellaterra. Universitat Autònoma de Barcelona (tesis doctoral inèdita).

CUADRADO, S.; DURÀ, A. y ESTALELLA, H. (2007): “Los cambios en la tipología de los asentamientos. El caso de la llanura del Alt Empordà (Girona)". Boletín de la Asociación de Geógrafos Españoles, n ${ }^{\circ}$ 33, 335-355. 
CUADRADO, S. y DURÀ, A. (2014): "Métodos cuantitativos y cualitativos para el estudio de los asentamientos urbanos". Anales de Geografía, no 34 (1), 61-85.

CUADRADO, S.; DURÀ, A. y SALVATI, L. (2016): "Not only tourism: Unravelling suburbanization, second-home expansion and 'rural' sprawl in a coastal area of Catalonia, Spain”, Urban Geography, DOI: 10.1080/02723638.2015.1113806.

DONAIRE, J.A. (2005): "La lògica espacial del turisme a la Costa Brava", en Debat Costa Brava. Congrés: Un futur sostenible, Girona, COAC, 218-225.

DONAIRE, J.A.; FRAGUELL, R.M. y MUNDET, LL. (1997): “La Costa Brava ante los nuevos retos del turismo". Estudios Turísticos, n 133, 77-96.

DONAIRE, J.A. y MUNDET, LL. (2001): "Estrategias de reconversión turística de los municipios litorales catalanes". Papers de Turisme, n 29, 28-49.

ESTEBAN, J. y TARROJA, A. (2004): Anuari territorial de Catalunya 2003. Barcelona. Societat Catalana d'Ordenació del Territori.

FERNÁNDEZ DURÁN, R. (2006): El tsunami urbanizador español y mundial. Madrid. Virus Editorial.

FERRAN, A. y CASAS, C. (Coords.). (2008): La cultura del no. El conflicte ambiental $i$ territorial a Catalunya. Vic. Eumo Editorial.

FRAGUELL, R. M. (1994): Turisme residencial i territori (la segona residència a la regió de Girona). Girona. L'Eix Editorial.

FRAGUELL, R. M. (2004): “Turisme de litoral a Catalunya. La pressió de la segona residència”, en Congrés de Turisme de Catalunya. Jornada I: Turisme, paisatge i ordenació del territori a Catalunya. Tarragona.

GAJA, F. (2008): “El 'tsunami urbanizador' en el litoral mediterráneo. El ciclo de hiperproducción inmobiliaria 1996-2006". Scripta Nova, vol. XII, n ${ }^{\circ}$ 270(66), 1 de agosto de 2008. Universidad de Barcelona. Disponible en http://www.ub.edu/geocrit/sn/sn-270/ sn-270-66.htm.

GARCÍA MONTALVO, J. (2006): "Deconstruyendo la burbuja: expectativas de revalorización y precio de la vivienda en España”. Papeles de Economía Española, no 109, 44-75.

GONZÁLEZ REVERTÉ, F. (2004): "Procés d'urbanització i desenvolupament residencial a Catalunya. Lectures territorials sobre el cas del Baix Penedès". Revista de Geografia, no 3, 35-62.

GUTIÉRREZ, O. y CASTAÑER, M. (2003): "Movilidad y estructuración de áreas urbanas: el caso de dos ciudades intermedias: Olot y Figueres", en La ciudad: nuevos procesos, nuevas respuestas (López Trigal, L.; Relea, C. E.; Somoza, J., Eds.). León, Universidad de León, 45-52.

INDOVINA, F. (2003): “La 'metropolizzazione del territorio'. Nuove gerarchie territoriali”. Economia e Società Regionale, $\mathrm{n}^{\circ}$ 21(3/4), 46-85.

MARTÍ, C. (2012): “Cambios recientes en el paisaje litoral de la Costa Brava”. Documents d'Anàlisi Geogràfica, no 58 (2), 239-264.

MAZÓN, T. y ALEDO, A. (2005): "El dilema del turismo residencial: ¿Turismo o desarrollo inmobiliario?", en Turismo residencial y cambio social (Mazón, T. y Aledo, A., Eds.). Alicante, CAM. FRAX. Universidad de Alicante, 13-30.

NAREDO, J.M. y MONTIEL, A. (2011): El modelo inmobiliario español y su culminación en el caso valenciano. Barcelona. Icaria. 
NEL·LO, O. (2002): Cataluña, ciudad de ciudades. Lérida. Editorial Milenio.

NEL·LO, O. (Ed.) (2003): Aquí, no! Els conflictes territorials a Catalunya. Barcelona. Editorial Empúries.

NEL·LO, O. (2012): Ordenar el territorio. La experiencia de Barcelona y Cataluña. Valencia. Tirant lo Blanch.

NOGUÉ, J. (Dir.) (2000): Atles de l'Alt Empordà. Barcelona. Institut Cartogràfic de Catalunya.

NOGUÉ, J. (2005): "La transformació del territori i del paisatge de la Costa Brava (19562003). Situació actual i propostes d'actuació”, en Debat Costa Brava. Congrés: Un futur sostenible. Girona, COAC, 88-121.

OBIOL, E.M. y PITARCH, M.D. (2011): "El litoral turístico valenciano. Intereses y controversias en un territorio tensionado por el residencialismo". Boletín de la Asociación de Geógrafos Españoles, $\mathrm{n}^{\circ}$ 56, 177-200.

OLIVER, J. (2005): "El model turístic de la Costa Brava a l'inici del S. XXI: estació d'enllaç o final d'etapa?", en Debat Costa Brava. Congrés: Un futur sostenible. Girona, COAC, 246-277.

PAVÓN, D. (2002): "Els canvis demogràfics", en Canvis socioambientals a l'Alt Empordà (1950-2000) (Ribas, A. y Saurí, D., Eds.). Girona, UdG, 45-67.

PAVÓN, D.; VENTURA, M.; RIBAS, A.; SERRA, P.; SAURÍ, D. y BRETON, F. (2003): "Land use change and socio-environmental conflict in the Alt Emporda county (Catalonia, Spain)". Journal of Arid Environments, $\mathrm{n}^{\circ}$ 54(3), 543-552.

PIÉ, R. (2005): “Ara toca fer ciutat" en Debat Costa Brava. Congrés: Un futur sostenible. Girona, COAC, 50-87.

ROCA, F. y MASSANA, C. (1972): "Estratègies urbanes i realitat urbana a la regió de Barcelona", en Economia crítica: una perspectiva catalana (Artal, F., Ed.). Barcelona, Edicions 62, 202-233.

RODRÍGUEZ LÓPEZ, J. (2006): "Los booms inmobiliarios en España. Un análisis de tres períodos”. Papeles de Economía Española, no 109, 76-89.

ROMERO, J. (2010): “Construcción residencial y gobierno del territorio en España: de la burbuja especulativa a la recesión. Causas y consecuencias". Cuadernos Geográficos, n ${ }^{\circ}$ 47, 17-46.

SÁNCHEZ, J.E. (2003): "El mercado inmobiliario y los promotores: cambios en la gran empresa inmobiliaria”. Scripta Nova, vol. VII, núm. 146(091), 1 de agosto de 2003. Universidad de Barcelona. Disponible en http://www.ub.edu/geocrit/sn/sn-146(091).htm.

SAURÍ, D.; BRETON, F.; RIBAS, A.; LURDÉS, J.C. y ROMAGOSA, F. (2000): “The ecological values of traditional land use in low-lying coastal environments: the example of the Aiguamolls de l'Empordà, Costa Brava". Journal of Environmental Planning and Management, $\mathrm{n}^{\circ} 43$ (3), 277-290.

SOLÀ MORALES, M. de (1974): "La urbanización marginal y la formación de plusvalía del suelo". Papers. Revista de Sociología, no 3, 365-380.

TARROJA, A. (2005): Anuari territorial de Catalunya 2004. Barcelona. Societat Catalana d'Ordenació del Territori.

TARROJA, A.; CASTAÑER, M. y MERCADÉ, M. (2006): Anuari territorial de Catalunya 2005. Barcelona. Societat Catalana d'Ordenació del Territori. 
TARROJA, A.; CASTAÑER, M. y MERCADÉ, M. (2007): Anuari territorial de Catalunya 2006. Barcelona. Societat Catalana d'Ordenació del Territori.

TATJER, M. (1979): "Propiedad inmobiliaria y espacio urbano. Aproximación a su estudio". Revista de la Universidad Complutense, $\mathrm{n}^{\circ} 115,49-82$.

TEIXIDOR, C. (1978): "Els agents de l'urbanisme" en Debat Costa Brava. Girona, Cambra Oficial de Comerç i Indústria, 31-34.

VALDUNCIEL, J. (2014): "Planeamiento urbanístico y forma urbana en Cataluña. El caso de la región de Girona (1979-2006). Boletín de la Asociación de Geógrafos Españoles, $\mathrm{n}^{\mathrm{o}} 65,71-86$.

VALENZUELA, M. (2007): "Cambio turístico y nuevos horizontes residenciales" en Los procesos urbanos postfordistas (Artigues, A.; Bauzà, A.; Blázquez, M.; González, J. M.; Murray, I. y Rullan, O., Eds.). Palma de Mallorca, Universitat de les Illes Balears. Asociación de Geógrafos Españoles, 261-302.

VERA, J.F. (2005): "El auge de la función residencial en destinos turísticos del litoral mediterráneo: entre el crecimiento y la renovación". Papers de Turisme, no 37-38, 95-114.

VICENTE, J. y GUTIÉRREZ, O. (2004): “La construcció d'habitatge a la demarcació de Girona, 1987-2003”. La Punxa, n 36, 6-54.

VILAGRASA, J. (1984): “Creixement urbà i producció de l'espai a Lleida (1940-1980)". Documents d'Anàlisi Geogràfica, no 5, 97-138.

VILLAR, A. y FERNÁNDEZ TABALES, A. (2013): "Diagnóstico y perspectiva territorial del golf en Andalucía: entre la cualificación turística y el desarrollo inmobiliario”. Boletín de la Asociación de Geógrafos Españoles, $\mathrm{n}^{\circ}$ 62, 357-378. 
